\title{
A MÚSICA COMO LINGUAGEM DOS OBJETOS E DOS AFETOS: UMA PERSPECTIVA A PARTIR DE WALTER BENJAMIN
}

\author{
Ana Judite de Oliveira Medeiros ${ }^{1}$ \\ Eduardo Lopes ${ }^{2}$
}

\begin{abstract}
Resumo
Numa perspectiva reflexiva sobre a música, este artigo aborda o alcance de sua linguagem, a objetivação que faz das coisas e a elaboração de afetos, como parte desenvolvimento do pensamento humano. Tomando como base a abordagem filosófica sobre a linguagem geral e humana (BENJAMIN, 2011) e o conceito de música como objeto virtual (LOPES, 2014), foram observados e analisados tais aspectos na peça musical Dança Lembrança do Sertão, da Série Bachianas Brasileiras, de Heitor Villa-Lobos. O exame da peça aponta como a linguagem musical dá visibilidade a diferentes afetos e identidades regionais, considerando sua apreensão por parte de quem a produz e de quem a recebe. E assim como é transmitida, a linguagem musical assume um caráter cognitivo, objetivo a fim de alcançar sua compreensão.
\end{abstract}

Palavras-chave: Música. Linguagem. Afetos.

\section{MUSIC AS A LANGUAGE OF OBJECTS AND AFFECTIONS: A PERSPECTIVE FROM WALTER BENJAMIN}

\begin{abstract}
Through a reflective perspective on music, this article addresses the scope of its language, the objectification it makes of things and the elaboration of affects, as part of the development of human thought. Based on the philosophical approach to general and human language (BENJAMIN, 2011) and the concept of music as a virtual object (LOPES, 2014), such aspects were observed and analyzed in the musical piece Danse Lembrança do Sertão, from the Bachianas Brasileiras Series, by Heitor Villa-Lobos. The examination of the play points out how the musical language gives visibility to different affections and regional identities, considering its apprehension on the part of those who produce it and those who receive it. And as it is transmitted, the musical language assumes a cognitive, objective character in order to achieve its understanding.
\end{abstract}

Keywords: Music. Language. Afects.

\section{Introdução}

Um olhar filosófico sobre a música suscita a reflexão do alcance de sua linguagem e da objetivação que ela faz das coisas, como parte desenvolvimento do pensamento humano. Para Theodor Adorno em Quasi una Fantasia. Escritos musicais (2018), a música assemelhase à linguagem, como um idioma musical. Em seu argumento diz que a linguagem da música indica o caminho para o intrínseco, bem como para o vago, e que a música se assemelha com a

1 Doutora em Sociologia e Música pela Universidade Federal do Rio Grande do Norte; Professora de Música do Instituto Federal do Rio Grande do Norte. E-mail: ana.oliveira@ifrn.edu.br

2 Doutor em Teoria da Música pela Universidade de Southampton (Reino Unido); Professor Associado com Agregação do Departamento de Música da Universidade de Évora, Portugal. E-mail: el@uevora.pt. 
linguagem na qualidade de sequência temporal de sons articulados, que são mais do que meros sons. Eles, os sons, dizem algo, que são frequentemente algo humano. Dizem tão mais enfaticamente, quanto mais à maneira elevada estiver a música. A sequência de sons converteuse em lógica: que nisto existe o certo e o errado. Porém, aquilo que foi dito não pode se depreender da música. Ela não compõe nenhum sistema de signos, mas comunica-se através deles, segundo o autor.

Por outro lado, ao longo dos séculos muitos autores têm se interessado pelo tema da música e sua linguagem. Do ponto de vista filosófico há um amplo argumento a partir de Descartes (1596-1650), Rousseau (1712-1778); e sob o ponto de vista biológico, com Charles Darwin (1809-1882). Para eles,

\footnotetext{
Tanto Rousseau (1781/1993) como Darwin (1871/1981) eram a favor de uma origem comum da música e da linguagem. Em seu livro sobre a origem da linguagem (1781/1993), Rousseau foi um fervoroso defensor da ideia de que as primeiras línguas foram cantadas, não faladas e Darwin considerava que a música evoluiu desde os convites de amor produzidos durante o período de reprodução para encantar as pessoas do sexo oposto: 'notas musicais e ritmo foram adquiridos pela primeira vez pelo homem ou progenitores femininos da humanidade por causa do charme do sexo oposto'. (Darwin, 1871/1981, p. 336 apud Besson, et al., 2011, p. 1).
}

Herbert Spencer (1820-1903) favoreceu a origem comum de música como linguagem, propondo uma teoria fisiológica para explicar sua função primária comum: expressar emoções. E do ponto de vista musicológico, durante o século 20, favoreceu a hipótese de uma origem diferente da música e da linguagem e, no século 21 , há uma renovação do interesse na comparação linguagem/música devido ao desenvolvimento da ciência cognitiva, dos adventos dos métodos de imagem cerebral e mais recentemente de avanços (e recuos) do projeto de equipar Inteligência Artificial com mecanismos capazes de realizar estruturas musicais com potencial emotivo - i.e. afetos (Cruz; Brisson; Paiva; Lopes, 2007).

Diante de diferentes posicionamentos, será então relevante esquadrinhar como o conhecimento musical é recebido, percebido e articulado, considerando que esse posiciona-se efetivamente como arte, e também como técnica, em que ambos não são opostos, mas em mútua cooperação. Neste sentido, Lopes (2021) refere o seguinte:

(...) um dos valores e qualidades da Arte e em particular da Música, é posicionar-se perfeitamente no ponto de divisão entre o universo físico/mensurável (e.g. frequências, durações) e o da imaginação/subjetivo (e.g. memória, afetos). A música é, deste modo, uma excelente realização daquilo que nos representa como humanos. Na realidade, a posição da música é de tal forma intermédia aos dois universos, que

n. 21

Janeiro - Abril 2021

p. $296-317$ 
funde num infinito nodal o objetivo e o subjetivo, podendo até, levado ao extremo, interrogar o que é (ou não é) música. (p. 18).

É exatamente esta interface que possibilita a eficácia da música como linguagem, e consequentemente, sua fruição. Por fruição, ou desfrute, lembramos uma das virtudes ou 'vantagens' da arte, sua fruição, que nos remete a desfrutar prazerosamente algo ou de algo, a qual tem por seu instrumento a linguagem. Eis o seu sentido, que não é apenas instrumental, mas, sobretudo, de como aborda totalidades, que de forma filosófica vem a esclarecer que a linguagem ajuda a formular proposições claras. Que nas palavras de Wittgenstein, "o fim da filosofia é o esclarecimento lógico dos pensamentos. (...) Cumpre à filosofia tornar claros e delimitar precisamente os pensamentos, antes como que turvos e indistintos" (2016, p. 112).

A fim de estabelecer uma relação livre e criativa entre a música e a realidade, apresentamos neste artigo a música como linguagem dos afetos, a partir do exame da peça musical Dança Lembrança do Sertão, da Série Bachianas Brasileiras de Heitor Villa-Lobos (1887-1959). Pensar através da música é estabelecer, a partir de sua linguagem, conexões trazidas por seus elementos mais fundamentais, como o ritmo, a melodia, e a harmonia, como esses representam e também refletem os diferentes contextos históricos em que são elaborados, como se comunicam, e que ideia trazem da realidade. Essas ideias chegam até ao ouvinte, que os processa de acordo com as referências do seu contexto e percepções pessoais. Neste encadeamento vemos o quanto a música não é um objeto autônomo, mas produto de um contexto, de um determinado período histórico, e também do pensamento humano.

Diante desta premissa, põe-se a seguinte questão: como é possível conceber através da música, da versatilidade de sua linguagem, outras ou novas definiçõos sobre uma região e sua cultura artística? Como expandir tais definições além de estereótipos historicamente construídos? Que, para esta questão, fazemos referência à região Nordeste, e em particular, a sub-região do Sertão. Relembramos que para o Sertão nordestino foram elaboradas definições históricas, como região que nasce e tem visibilidade a partir do fenômeno das secas, de natureza incorrigível (Cunha, 1987), de simplicidade quase rústica, e de forte influência ibérica, sobretudo, de mouros e judeus (Cascudo, 2001). Tais definições, apesar de coincidirem, foram cristalizadas quase que imutáveis, como sua verdade, e assim mantendo-se intocadas em nome da tradição (Holanda, 1996; Cascudo, 2001; Ortiz, 2006). É em reflexão sobre a linguagem musical, que apresentamos como é possível revelar, outras ou novas formas de construir afetos e identificação com uma região e sua cultura musical. 
Considerando haver diferentes formas de construir esses afetos e identificações, salientamos que esses dão-se a partir da relação entre o indivíduo, sua realidade e a objetividade que faz, como se inserem e transformam a percepção dos objetos e, consequentemente, dá-lhes outra. Esse é o motivo pelo qual trazemos uma reflexão filosófica sobre a música, que através da educação musical, aponta para infundir um espírito crítico, como parte da construção de uma sociedade mais ativa e participativa, que busca mover-se para o futuro, em ponderação com o passado e alargando o presente, se aqui consideramos a ecologia dos saberes (Souza, 2001).

Com o objetivo de desenvolver essa reflexão, trazemos a música como a linguagem dos objetos e dos afetos, sob uma abordagem de Walter Benjamin (2011); o qual faz uma alusão à literatura, a narrativa, como essas formas constroem uma ideia e as comunica. E que, na análise da peça Dança Lembrança do Sertão, como sua linguagem musical dá visibilidade a diferentes afetos que se fizeram e refizeram na região, considerando sua apreensão por parte de quem a produz e de quem a recebe. Assim como é transmitida, a linguagem musical assume um caráter cognitivo, objetivo a fim de alcançar sua compreensão. E que nessa perspectiva, é o conceito de música como ‘objeto’ virtual (Lopes, 2014), que nos chama atenção a partir da utilização de metáforas (Lakoff \& Johnson, 1980).

O motivo pelo qual esse tema vem à superfície, surge do particular interesse na investigação e atuação no ensino de música, que chamamos atenção para o alcance reflexivo da linguagem musical. Pensar a música como linguagem dos objetos e dos afetos, dá-nos a oportunidade e impulsiona ir além, o que nos fazer sentir mais humanos, apesar de toda informatização do cotidiano.

\section{A Dança Lembrança do Sertão das Bachianas Brasileiras}

A peça musical Dança Lembrança do Sertão, que trazemos neste artigo como linguagem das coisas e linguagem do homem, é parte da Série Bachianas Brasileiras do compositor Heitor Villa-Lobos. A Série Bachianas consiste em uma obra sequenciada em nove suítes compostas para diversos grupos instrumentais e vocais. Sua estrutura remete diretamente à música de Johann Sebastian Bach (1685-1750), por isso "bachianas", e ainda com traços do impressionismo francês e do romantismo alemão. Cada suíte funde-se de maneira própria com a música folclórica e popular, especialmente o estilo do choro e a musicalidade sertaneja, denominando assim o título duplo "Bachianas Brasileiras". A Série Bachianas Brasileiras tornou-se uma síntese entre a matriz musical brasileira e a linguagem de Bach, que orientou 
Heitor Villa-Lobos a olhar para o folclore musical, dando-lhe um tratamento "bachiano", a fim de elevá-lo ao patamar universal, sendo, igualmente, parte do pensamento modernista de Mário de Andrade sobre a música nacional.

Da Série Bachianas Brasileiras foram selecionadas quatro peças musicais, as que trazem o tema do Sertão nordestino em evidência, que são: a Introdução Embolada, da Bachiana $\mathrm{n}^{\circ}$ 1, composta em 1932 para oito violoncelos; a Dança Lembrança do Sertão, da Bachiana ${ }^{\circ}$ 2, composta em 1933 para orquestra, e depois em uma versão para piano solo em 1941; o Coral Canto do Sertão e a Ária Cantiga, ambas da Bachiana n ${ }^{\circ}$, compostas para piano solo em 1931, e com versão orquestrada em 1941. Nessas peças foi observado como o compositor inseriu estrategicamente elementos rítmicos e melódicos, a exemplo do baião, da embolada e temas de canções populares, permitindo, assim, a construção de um imaginário da região, que foram ouvidas e investigadas em acurado exame documental e empírico. Dessas peças consideramos suas características composicionais aliadas à cultura musical do Sertão, de onde seus traços dão originalidade à obra, sendo reconhecidos neles, cantos e rituais indígenas e africanos, como cantigas e lundus, aliados à influência ibérica moura, cantada no interior dos sertões nordestinos, as quais denominamos de Bachianas Sertanejas.

Tomando como exemplo a Dança Lembrança do Sertão, trazemos as reflexões de Walter Benjamim sobre o 'narrador' e atribuímos a Villa-Lobos, pelo paciente trabalho de escuta à condição de 'narrador do sertão'. Da sua prática, como ouvinte e depois narrador, como foi capaz de reconhecer a diversidade cultural, realizar um trabalho de tradução intercultural, portanto, de ecologia dos saberes, fazendo com que sua obra assumisse a dimensão universal.

O diálogo que ele estabelece entre a obra de Johann Sebastian Bach e a cultura popular nas diversas tradições culturais brasileiras constitui um claro trabalho de tradução intercultural que trazemos, sobretudo, pelo trânsito que tem a sua linguagem. Isso fica ainda mais evidente nas Bachianas Sertanejas, que reportam a determinadas tradições musicais do sertão brasileiro, especialmente, do nordestino.

\section{Uma linguagem objetivada}

Ao considerar a música, em sua escrita, com estrutura de escalas, acordes e desenhos rítmicos, essa música também se constitui como 'objeto' virtual, o que contribui para a compreensão e sua interpretação. Isso nos faz refletir o potencial da música, e o que significa 
considerar sua essência, sua ideia, não necessariamente sujeita a alterações, porque o que muda é a percepção e a compreensão que se tem sobre a obra como 'objeto' e o tema que ele aborda.

Trazer a música, ou compreendê-la como um 'objeto' virtual, tem a ver com a objetivação que fazemos da música, a dizer que tem profundidade, tem altura, que "sobe" e "desce"; que tem intensidade mais "forte" ou "fraca"; duração que pode ser mais rápida ou lenta, sendo essas construções, do ponto de vista cognitivo, que nos possibilitam compreender a música como um objeto de diferentes formas, texturas e construções mentais (Lopes, 2014). Essa é uma forma de falar metaforicamente da música, comparando-a com a arquitetura, como um objeto em três dimensões, com altura, largura, profundidade, termos utilizados para comunicar a ideia musical, que, no entanto, na realidade, não possuem dimensões reais, mas virtuais, imaginadas.

A percepção da obra como objeto virtual cuja utilização está em metáforas (Lakoff \& Johnson, 1890) contribui para a objetivação do objeto musical e sua construção mental. O uso de metáforas, com a finalidade de objetivação da linguagem musical, vai ao encontro das ideias clássicas, as quais afirmam que elas não são somente utilizadas na linguagem poética, mas também fazem parte da comunicação cotidiana, como parte do sistema cognitivo humano, estando, dessa forma, no pensamento e não apenas na linguagem.

Ao trazermos metáforas à música, essas se destinam à comunicação mais ampla e de conexões com outras ideias em que há uma projeção de dois domínios conceituais: um cognitivo, de natureza concreta e experiencial; e o outro sensorial, de caráter mais abstrato, em que ambos permitem compreender o domínio-alvo, o alcance da ideia musical, não necessariamente aquilo que é real como também o imaginado, a fim de elaborar e atribuir ideias sobre a imagética de uma região.

Sendo a música um objeto virtual, de denominações metafóricas, também é uma linguagem temporal, isto é, que só existe no tempo em execução (kronos), tendo sentido singular para quem ouve, porque é reformulada como resultado ou produto do que anteriormente foi elaborado. Isso porque tudo o que fora formulado a respeito da música desde seus elementos perceptíveis como altura, intensidade, duração e timbres - está sujeito a transformações, e já foi transformado (Gestalt), permitindo que a nossa percepção seja alterada por inúmeros fatores que nos cercam: o contexto histórico, o acesso à obra e até a própria percepção pessoal, tornando a construção das coisas ligadas ao processo cognitivo, com a interpretação do ver e do ouvir sob novos e diferentes prismas. 
Sendo a nossa percepção constantemente alterada, isso não faz com que o 'objeto' de nossa observação e investigação mude, mas que, a partir dele, abram-se possibilidades e novas interpretações, por ser essa a parte do processo cognitivo para a construção das coisas, como parte daquilo que somos, do nosso tempo, da nossa percepção da realidade. É o processo cognitivo que dá objetividade à arte, não apenas como uma reprodução do mundo, porque o que chamamos 'objetivo' (por isso entre aspas) está selecionado à luz de seu significado cultural e igualmente explicado em termos históricos ou causais, visto que por mais explicativos que sejam, são incapazes de reproduzi-los em sua totalidade.

Nessa perspectiva, trazemos brevemente o que se diz a respeito da unificação das ciências culturais e sociais (Weber, 1989), apesar de não ser este o foco do artigo, e por isso não nos detemos mais profundamente às questões apontadas pelo autor sobre a objetividade da cultura. Para Weber (1989), não há análise puramente objetiva sobre os fenômenos culturais, independentemente de perspectivas particulares, mesmo que selecionadas e diluídas. A razão disso reside no propósito cognitivo dos projetos científicos sociais. Quando se quer compreender a realidade nos aspectos característicos e o significado cultural de seus fenômenos particulares em sua forma contemporânea, não há outro modo além de recorrer à historicidade.

Apesar de não ser a análise objetiva o alvo do que trazemos, tomamos seu posicionamento e referência por assumir que não há uma análise pura dos fenômenos culturais e, principalmente, por considerar importante buscar compreender a realidade do objeto cultural, a linguagem musical na contemporaneidade. Da importância trazida pela objetividade, o que nos detemos é a sua relevância cognitiva como linguagem musical.

\section{A música como linguagem dos Objetos e dos Afetos}

Sob a abordagem filosófica da linguagem em geral, que nos referimos a dos Objetos e a linguagem do homem, dos Afetos, Walter Benjamin (2011), refere-se a linguagem a partir de uma crítica literária que faz, a fim de evidenciar a necessidade de existir a obra de arte, do modo a apreender seu ideal a priori. Esse ideal, por sua vez, é para ele a lei fundamental do organismo artístico, que só pode ser redimido pelo reconhecimento de uma unidade estética fundamental entre a forma e a matéria. Para dizer de outra maneira, o crítico deve ter consciência de que não há forma separada de teor (Gehalt), termo chave na reflexão de Benjamin, porque anula a posição estéril entre o "conteúdo" e a "forma". Dessa maneira, tem- 
se a consciência de que a forma nunca existe sem teor, porque surge de um desdobramento da filosofia da linguagem desenvolvida pelo autor, o que, por sua vez, atesta a importância da reflexão sobre a linguagem estética, quando afirma que a língua é uma essência espiritual, e imediatamente aquilo que é comunicável, porque "toda língua se comunica por si mesma, no sentido mais puro, o meio Medium da comunicação" (Benjamin, 2011, p. 54).

Trazendo ao enfoque deste artigo, a música como linguagem dos Objetos e dos Afetos, essa posiciona-se também por meio daquilo que representa como o Medium, isto é, como linguagem, ampla e articulável. Ao tomar como exemplo da peça Dança Lembrança do Sertão da Bachiana ${ }^{\circ}$ 2, da Série Bachianas Brasileiras, observa-se em sua escrita (Figura 1, as linhas), como decorre a ideia fluída de uma melodia em toada, a qual aproxima a ideia de Sertão, sendo essa sua representação como linguagem escrita.

A peça foi escrita na versão para piano em 1941, e nela estão dispostos arpejos em oitavas numa sequência em arabescos impressionistas de Debussy, acompanhados de uma melodia em tonalidade menor, com ethos de "saudade", em comparação ao Sertão como o lugar da saudade. O termo Medium é uma referência ao clima, visto que evoca mais que uma paisagem sonora, e uma linguagem poetificada da região, ou seja, aquilo que preexiste a ela e nela se realiza.

A Dança Lembrança do Sertão, escrita para andamento Andantino moderato, quaternário e na tonalidade de Lá menor, na versão para orquestra em 1933, inicia com pizzicati das cordas seguido de staccatos, evocando o dedilhado da viola sertaneja. Após uma breve introdução, o tema aparece em solo de trombone que expõe uma sonoridade "agreste" sem muitas ondulações com terminação na $7^{a}$ abaixada, que caracteriza a escala nordestina ${ }^{3}$ (Figura 2).

O solo segue em diálogo com flautas, oboé e clarinetes, em escalas ascendentes, acentuando a característica nostálgica através do recurso do pizzicati, diferentemente do ambiente sonoro em Allegro que constitui a seção central da Dança. Seu ethos comunicativo se nutre no Allegro em que o compositor explora com intensidade as potencialidades rítmicas implícitas no tema, que após uma densa "fúria" rítmica estabelece um andamento mais calmo para a reexposição do tema que termina em uníssono.

A escala denominada de 'nordestina' consiste em uma sequência de notas musicais oriundas da organização mixolídia, dos modos ou organização musical grega. Essa sequência melódica chega ao Brasil com a colonização ibérica no século XVI, que no Nordeste do país, são acolhidas e difundidas na arte popular. A escala nordestina é encontrada na música popular de tradição oral, como em toadas, aboios e cantigas (Explicação da autora)

n. 21

Janeiro - Abril 2021

p. $296-317$ 
Por preexistir uma linguagem poetificada da região não significa que seja em fixidez, mas, a partir de superfícies rígidas - conceituadas anteriormente. Para Ingold (2011), a linguagem musical desenvolve-se para pensar as fluências desse amplo Medium, que é o ambiente onde existimos e por onde nos movemos. Segundo o autor, são interferências que compõem uma linguagem como um todo, com a descrição de ventos, chuvas, sazonalidades do ambiente pensado e representado, considerando a criatividade do compositor.

Sob a abordagem benjaminiana, observa-se que na peça musical, denominada de Bachianas Sertanejas (Medeiros, 2020), é possível incluir a definição climática e não apenas pictórica sobre a região. Nesse processo, a abordagem filosófica da linguagem, desenvolve-se sob o conceito poetificado de Das Gedichtete, isto é, o poema, no ensaio de Hölderlin. Esse filósofo, poeta lírico e romancista alemão conseguiu sintetizar na sua obra poética o espírito da Grécia antiga sobre a natureza do ponto de vista romântico e uma forma não ortodoxa de cristianismo, alinhando-se aos poetas germânicos. Sob essa ótica, Benjamin (2011) traz o poeta alemão para designar justamente a condição do poema, ou seja, aquilo que, em certa medida, preexiste a ele e nele se realiza.

Para Benjamim, o "poetificado" revela-se como passagem da unidade funcional da vida para a do poema, de sorte que, naquilo que é poetificado, a vida se determina por meio do poema; sendo essa uma tarefa da linguagem. Na peça Dança Lembrança do Sertão o poetificado refere-se à região, como ela é, viva e produtiva, entretanto, e também como a música em linguagem imagética e espiritual do compositor, traz a superfície outro prisma.

É na linguagem que o homem comunica sua essência espiritual, designadora, em que acentuamos essa, ir muito além da representação climática. Mas, como linguagem designadora, torna-se interessante ao ser capaz de permitir que a essência espiritual se comunique em palavras, em sons. "Mas, mesmo que incorra no erro de fazer desta linguagem designadora a linguagem geral, perde-se a possibilidade de uma compreensão mais profunda e íntima das coisas" (Benjamin, 2011, p. 50).

\subsection{A música como a linguagem do narrador, a linguagem dos Afetos}

O autor ainda destaca na essência da linguagem a figura do narrador e reflete seu desaparecimento na história da civilização, ao que assemelhamos ao compositor diante da sua obra, apesar de este não haver desaparecido. Isso discorre sobre a importância da narrativa e traz algumas observações em que destaca a sabedoria, a informação e a experiência. Ele parte

\begin{tabular}{|l|l|l|l|l|}
\hline Govista Dialeatus & Ano 10 & n. 21 & Janeiro - Abril 2021 & p. $296-317$ \\
\hline
\end{tabular}


do trabalho do escritor Nikolai Leskov, que foi um polêmico romancista russo ao tratar do tema anti-niilista sobre o pensamento religioso, numa época em que o niilismo era amplamente disseminado entre os grandes escritores russos e franceses. Benjamin traz esse escritor para defender a tese de que a arte de narrar histórias está em extinção, e de como a guerra fez com que os combatentes ficassem mais pobres em experiência comunicável.

Não obstante, aos nossos dias, isso se aplica também porque ouvimos muito, em guerra com os nossos próprios sentidos. Ouvimos talvez compulsivamente, mas não escutamos; e se escutamos, não compreendemos; e se compreendemos, não nos emocionamos. Porque se perdeu a capacidade de narrar, de experienciar, de envolver-se com o objeto em audição, em sua totalidade como objeto artístico e cognitivo. Esse parêntese na abordagem benjaminiana faz-nos lembrar das primeiras experiências numa audição reflexiva e crítica, ainda nos primeiros anos de formação musical.

Benjamim (2011, p. 198) afirma que as melhores narrativas são "as que menos se distinguem das histórias orais contadas pelos inúmeros narradores anônimos", isso porque esses narradores dividem-se em dois tipos: o narrador que vem de longe, que na obra de Leskov (2012) é o marinheiro comerciante; e o narrador que vive sem sair de seu país e conhece bem a tradição, na figura do camponês sedentário. Nessa comparação, está a extensão do real do reino narrativo que só pode ser compreendida se levarmos em conta a interpretação desses dois tipos, nos quais enquadramos o compositor Heitor Villa-Lobos na peça Dança Lembrança do Sertão, como um "narrador" do Sertão nordestino, que necessariamente não esteve em todos os lugares, mas cita sua aventura musical pelo Brasil profundo; também se pode descrevê-lo como o "marinheiro" ou "camponês".

Ao falar sobre o narrador, seu ofício, sua ligação com o trabalho manual, salientamos a importância da sabedoria, e principalmente, o quanto esse conceito está desaparecido, "a arte de narrar está definhando porque a sabedoria - o lado épico da verdade está em extinção" (Benjamin, 2011, p. 201). Destaca dois indícios da evolução que culminarão na morte da narrativa: o romance e a informação. O romance, diferentemente da narrativa, está ligado ao livro, que não procede da tradição oral nem dela se alimenta, sua origem é o indivíduo isolado, que não recebe nem sabe dar conselhos. Já a informação, salienta o autor, ainda é mais ameaçadora e provoca uma crise no próprio romance. Que trazendo ao nosso tema, vemos como a informação sobre o Nordeste e o Sertão, e todo o conceito construído sobre a região, impede de ser visto de outra forma, sendo sua conceituação reproduzida nas artes, na mídia, nos “arremedos" de sotaques e expressões, como alerta Albuquerque Júnior (2011). 
Voltando à narrativa, diferentemente de seu saber que vem de longe, a informação é imediata e pede uma verificação imediata também, porque esta só tem valor enquanto é nova. A esse respeito, apontamos uma inquietação: o que impede de verificar a distribuição de informação e reprodução conceitual sobre a região já tão apegada ao passado? A quem interessa manter?

Tratar a Dança Lembrança do Sertão como uma narrativa, apontamos para uma possível outra interpretação da região, que necessariamente não precisa apagar as demais definições construídas, mas redefini-las, olhar para frente, para o que se tem hoje e o que poderá construir no futuro. Talvez seja cômodo alimentar-se do passado, apontar seus erros e também os acertos, mas continuar a reproduzi-los não mais cabe no presente, no século XXI. Há uma urgência em caminhar, porque como a erosão do tempo muda a paisagem, as pessoas mudam suas concepções, e, para mantê-las vivas, é necessário renovar a forma de ver também o passado.

Um dos pontos que destacamos é a relação entre a narrativa e o trabalho manual. A narrativa é ela própria uma forma artesanal de comunicação, em que o narrador "deixa sua marca" contada, como o compositor deixa a sua, na obra que escreve. A narrativa torna-se tão particular, quer seja do autor, do compositor, a qual Benjamin ainda salienta sua importância como a dos mestres e sábios (2011, p. 208). No caso do compositor, em sua função de narrador, dar seus 'conselhos' não para alguns casos, como o provérbio, mas para muitos casos, como o sábio sob seu olhar experiente ou até curioso, pois pode recorrer ao acervo de toda uma vida. "Seu dom é poder contar sua vida; e sua dignidade, é contá-la inteira. O narrador é o homem que poderia deixar a luz tênue de sua narração consumir completamente a mecha de sua vida" (Benjamin, 2011, p. 208).

Heitor Villa-Lobos, em sua experiência com a cultura sertaneja, de perto ou de longe, permitiu percebê-la como é, e incluir em parte de sua obra. Nesse processo, a identidade na produção artística pode ser fruto de seu reconhecimento como prática social, uma espécie de foco virtual que é indispensável para o artista. Lévi-Strauss (2008, p. 369), após sua experiência com comunidades indígenas nos estados do Mato Grosso e de São Paulo, reconhece que "a identidade é uma espécie de foco virtual ao qual nos é indispensável referir para explicar certo número de coisas, sem que tenha jamais uma existência real”.

Para Lévi-Strauss, há na existência puramente teórica um limite que não corresponde à realidade. Seu alerta é para a necessidade de descartar a identidade como uma entidade dotada de existência própria e não se pode negar que ela é na vida cotidiana. Mas

n. 21

Janeiro - Abril 2021

p. $296-317$ 
também é um referencial para a percepção do social e do próprio indivíduo, como ideia ou noção, que permite perceber o mundo e como é dotado de sentido.

Essa identidade com sentido estaria ligada diretamente à história e a seu contexto vivido. Para Lévi-Strauss, a história não está ligada ao homem, nem a qualquer objeto em particular, mas consiste inteiramente no seu método: a experiência, que comprova o que é indispensável para a integralidade de qualquer estrutura humana. Longe, portanto, de a pesquisa da inteligibilidade resultar na história como o seu ponto de chegada, "é a história que serve de ponto de partida para a busca de inteligibilidade. Assim como se diz de certas carreiras, a história leva a tudo, mas contanto que se saia dela" (Lévi-Strauss, 2008, p. 371).

Considerando a historicidade da cultura musical do Sertão nordestino e como foi incluída na música de Villa-Lobos, percebe-se que isso não depende apenas de sua vivência, mas também da forma como o compositor a incorporou, no seu próprio método, considerando o nacionalismo de sua época e as influências modernistas e neoclássicas. É essa música e esse Sertão que se tornam mais presentes também por sua intensidade e representatividade brasileira, os quais o compositor buscava em suas referências. Foi um Sertão impressionista, debussyniano, cujas formas emergem entre luz e sombra, cores e imagens que se formam na retina, para lembrar Monet, e que se move entre um passado conceituado e um presente a ser (re)descoberto.

Sob a lógica benjaminiana, em comparação com a literatura, o romance e a narrativa aplicam-se à música, em sua abordagem. Ele sempre volta à questão de que a arte de dar conselhos está em extinção, isso porque a sabedoria repete o lado épico da verdade. Ademais, ela está em extinção, bem como a transmissibilidade das experiências devido à evolução das forças produtivas. O surgimento do romance vai culminar com a morte da narrativa. Nesse caso, o narrador retira da experiência o que ele sabe, enquanto o romance não tem essa característica, não recebe nem dá conselhos.

O romancista descreve o incomensurável numa vida humana até seus últimos limites, diferentemente do que ocorre na narrativa que se constrói da experiência e conduz o ouvinte a dela participar pela sua força épica. Entretanto, as transformações das forças épicas, das quais a narrativa se alimenta, passaram por transformações milenares semelhantes às da crosta terrestre. Mas o romance encontra na burguesia, no capitalismo, terreno propício ao seu desenvolvimento, principalmente com a imprensa, um dos seus instrumentos, como uma nova forma de comunicação. Em contraposição à narrativa está a informação, sendo plausível e incompatível com a narrativa, esta que prima em evitar explicações, porque, diferentemente da

n. 21

Janeiro - Abril 2021

p. $296-317$ 
informação, na narrativa, o leitor ou ouvinte é livre para interpretar, para refletir sobre o distanciamento, devido ao tema que lhe é apresentado.

A narrativa, ao contrário da informação e do romance, conserva suas forças, seu desenvolvimento; enquanto a informação, por si mesma, perde o valor ao se ter conhecimento dela. $\mathrm{O}$ narrador, renunciando às sutilezas psicológicas, faz do tédio o tecido da experiência, que o capacita a contar e recontar histórias, seja no ritmo do seu trabalho, seja no esquecimento de si mesmo. Nessa perspectiva, trazemos a experiência de Villa-Lobos com músicos cearenses, em especial, com o saxofonista Donizete, quando relatou que esses músicos afinavam seus instrumentos mais para baixo e cantavam como se se aproximassem do diapasão normal, mas não chegavam a ele, o que, para eles, soava "normal” (Mariz, 1989; Maia, 2000). Interessoulhe, naquele contexto, a experiência de outras referências musicais, que se lhe faziam contemporâneas também.

Assim, o compositor buscou trazer essas referencias à sua obra, considerando a peculiaridade da música que havia conhecido, não em alteração ou "correção" ao diapasão normal, mas como um "narrador" nesse processo, esquecer-se um pouco de si mesmo e apresentar o outro, a novidade que viria aparecer em sua obra. Esse era o seu "trabalho manual", a sua narrativa, reproduzido inicialmente em taquigrafia, propício ao desenvolvimento da arte de narrar, talvez rupestre e intuitivo, como ficou conhecido, mas elaborado e muito sofisticado com a arte da Bach.

A narrativa não está preocupada com a pureza do que está sendo narrado, como Villa-Lobos também não estava preocupado em relação a tudo quanto escrevia. Era apenas fiel à sua imaginação, à sua narrativa de Sertão, que necessariamente não teria de ser naturalista, mas impressionista. Os narradores geralmente começam a narrativa descrevendo as circunstâncias em que apreenderam os fatos, as camadas finas do tempo e do labor que entalhavam as narrativas, até as que já não existem mais. Nessa direção de narrativa, observamse tais descrições na Dança Lembrança do Sertão da Bachiana ${ }^{\circ}$ 2, em que camadas de impressões lhe são dadas através do tratamento técnico dado à obra, em termos weberianos, quando dizia respeito à escrita musical e como ela representava a ideia do compositor.

Benjamim (2011) ainda compara a arte de narrar com as ideias de eternidade e morte, antes ligadas ao trabalho prolongado, à comunicabilidade da experiência da arte de narrar. A morte foi depurada dos espaços burgueses, dando espaço ao poético naquilo que os desviava da realidade. Mas a lógica do autor se desenvolve em torno da autoridade do leito de morte, que foi perdendo a significação na condição de exemplo aos vivos, sendo a origem

\begin{tabular}{|l|l|l|l|l|}
\hline Govista Dialeatus & Ano 10 & n. 21 & Janeiro - Abril 2021 & p. $296-317$ \\
\hline
\end{tabular}


reflexiva da narrativa. Ele traz a figura de Hebel, de modo que o narrador faz uma cronologia de uma história de amor, de uma noiva de um dos mineiros de Falum, e usa a morte de forma tão regular que nela exemplifica bem sua importância na arte de narrar, comentando a ideia da historiografia como zona criadora em relação às formas épicas. Seja cronista, seja narrador, está livre da obrigação do ônus verificável, e nisso revemos a trajetória de Villa-Lobos, como "narrador" dos Sertões que visitou, ora afirmada por seus biógrafos, ora rebatida nos estudos historiográficos sobre o compositor, em pouco confirmada e em muito trazida para sua obra.

Trata-se de uma narrativa substituída pela exegese, que não se preocupa com o encadeamento de fatos determinados, apenas com a inserção deles no fluxo insondável das coisas, a que Villa Lobos está vinculado, porque, dialeticamente, tem as "deixas" do narrador e segue em suas concepções sobre o que lhe foi apresentado. Esse não é um caminho difícil de percorrer, porque, o verdadeiro narrador tem raízes no povo e com ele cria afetos, laços que o identificam.

Em relação a Villa-Lobos, suas raízes estavam no povo, seja no Rio de Janeiro boêmio dos anos de 1920, com as serestas e chorões; seja no interior de São Paulo, com as cantilenas sertanejas caipiras; seja nos sertões profundos no Nordeste do Brasil, com os jongos da Bahia, os maracatus do Recife e as cantigas cearenses. É uma camada artesanal que tece a narrativa e conduz assim o ouvinte. "Porque os narradores têm a facilidade de moverem-se para cima ou para baixo, e não impõe sua verdade, mas constrói sua narrativa a partir dos elementos que dispõe" (Benjamin, 2011, p. 210).

Sob esse prisma, lembramos a declaração de Villa-Lobos sobre ser ou não moderno e escrever música dissonante, quando esteve no Ceará e ouviu cantar de maneira diferente ao seu diapasão normal, como se estivesse desafinado. Em vez de corrigir, percebe que se trata de outra afinação, que exatamente a sua não significa "perfeição", dando-lhe curiosidade em compor a partir daquelas referências musicais.

A experiência musical do compositor com outros músicos mostra-nos sua posição de narrador na lógica benjaminiana. Ele traz a voz da experiência para sua música. Nessa direção, Benjamin (2011) ao comentar A voz da natureza, de Leskov, mostra que esta se exprime menos através da voz humana, e mais pela "voz da natureza". A esse respeito, percebemos que, na Dança Lembrança do Sertão e no Coral Canto do Sertão, ao evocar essa voz não humana, Villa Lobos dá lugar ao fato, à paisagem, ao Medium - como mediação climática para a paisagem sonora. 


\subsection{A música como linguagem dos Objetos}

Na observação do artista, de acordo com sua percepção mística, como trata Benjamin, os objetos iluminados perdem os seus nomes. Assim, sombras e novas claridades formam sistemas particulares, que não dependem de qualquer ciência, nem aludem a uma prática, mas esses recebem toda a sua existência e todo seu valor, porque são "de certas afinidades singulares entre a alma, o olho e a mão de uma pessoa nascida para surpreender, que tais afinidades se reproduzem em si mesmo para as produzir" (Benjamin, 2011, p. 215).

Sob essa ótica, pode-se tecer a linguagem da "Lembrança do Sertão", seja em Medium, seja em experiência com músicos locais, seja, ainda, em impressões que foram se construindo sobre a região. Lembramos a figura do narrador como mestre e sábio, que sabe dar conselhos, não como os provérbios, mas, em muitos casos, pode carregar os arquivos de uma vida. Busca ele contar ou descrever sem fragmentos, sem visão exógena e preconceituosa, mas contá-la sem deixar a luz tênue de sua narração consumir a mecha da vida ..., o narrador é a figura na qual o justo se encontra consigo mesmo.

Essa certamente é uma linguagem geral, que significa ou também aponta para a linguagem do homem como homo ludicus e em contribuição à comunicação de conteúdos espirituais, que se refletem nos domínios da técnica e a arte como elemento social, em potencial. Nessa abordagem, a linguagem não envolve somente a comunicação, mas também todos os aspectos da vida humana. Porque tudo o que tiver relação com o homem possui uma linguagem (Benjamin, 2011), o que não se trata de nenhuma novidade, mas que o autor divide em "linguagem dos homens", que aqui trazemos dos afetos e, "linguagem em geral", dos objetos. A existência dessa linguagem estende-se não apenas a todos os domínios de manifestação espiritual como também em todos os sentidos, porque a linguagem pertence absolutamente a tudo, e não há evento, tanto na natureza animada quanto na inanimada, em que não haja uma linguagem. Ela é essencial naquilo que comunica.

Dessa forma, percebe-se que a linguagem não se limita à vida humana, ela está presente em tudo o que existe na vida do homem, no restante da criação. Na concepção tradicional de linguagem, ao contrário dessa ideia, só existiria linguagem no âmbito humano. Assim, somente o ser humano tinha capacidade para manifestar linguagem, para desenvolver uma forma de se comunicar, o que ficaria incompleto, a nosso ver, sendo aquilo que falta às teorias mais modernas da linguagem. 
Nessa perspectiva, estamos de acordo com Benjamin, em sua concepção mais ampla sobre a linguagem dos objetos. Isso porque, entendemos ter a arte, a música, em particular, a sua própria linguagem. Esse pensamento leva-nos à seguinte pergunta: como as coisas se comunicam? Sobre isso, Benjamin (2010, p. 218) vai responder: "A quem se comunica a lâmpada? A quem a montanha? E a raposa? - Aqui a resposta é: ao homem. Não se trata de antropomorfismo. A verdade dessa resposta se deixa ver no conhecimento, talvez também, na arte".

\section{Considerações Finais}

Diante do exposto, ao trazermos a Dança Lembrança do Sertão, da Bachiana $\mathrm{n}^{\circ} 2$, buscamos, por essa teoria, compreender como se dá a peça musical como linguagem. Em comparação com um artista plástico, quando esse observa um cavalo correndo ou o pôr-do-sol, ele capta essa imagem pelos seus sentidos. Na pintura dessa imagem, que está em sua memória, busca expressar aquilo que sentiu ao visualizá-la. A pintura pode ser considerada fruto da comunicação concebida, de modo silencioso, entre o pintor e o seu objeto. Na Dança Lembrança do Sertão, como Bachiana Sertaneja, as imagens que comunicam a região, na obra, são trazidas primeiro na memória do compositor e depois na do ouvinte. Delas fazemos ainda faz a seguinte analogia: "Se a lâmpada e a montanha e a raposa não se comunicassem ao homem, como poderia ele nomeá-las? No entanto, ele as nomeia ele se comunica ao nomeálas" (Benjamin, 2011, p. 220).

Eis a diferença entre a linguagem dos objetos e dos afetos. O que não existe nos objetos, seria "uma linguagem nomeadora". Dessa forma, podemos dizer que tanto o homem como as coisas são possuidores de linguagem. Assim, há linguagem tanto em Villa-Lobos como nas Bachianas, como no Sertão, uma vez que não podemos desprezar a força dessa linguagem; porque "às coisas é negado o puro princípio formal da linguagem que é o som" (Benjamin, 2011, p. 220). Isso significa dizer que a linguagem dos objetos é silenciosa; e a linguagem dos afetos, é nomeadora e sonora.

Apesar de parecerem separadas, ambas as linguagens não estão em oposição. Elas se complementam, entre o silêncio de uma e a sonoridade da outra, sem que haja necessariamente uma relação de poder, mas mútua cooperação. Há dois termos na língua alemã trazidos por Benjamin (2011) que são: Mittel, que significa "meio para determinado fim" e 
Medium, que significa "meio enquanto matéria, ambiente de modo de comunicação", ambos se referem ao meio em que ocorre a linguagem.

Na concepção tradicional ou "burguesa", assim por ele chamada, é a de que "o meio [Mittel] da comunicação é a palavra; seu objeto, a coisa; seu destinatário, um ser humano" (Benjamin, 2011, p. 223), sendo esse meio o intermediário da comunicação, que serve para relacionar as coisas e o que se diz delas. Nesse processo, a essência do signo parece ser a de um ente mediato, isto é, algo que está por outra coisa. Esse signo seria, portanto, um instrumento, uma ferramenta utilizada para dar sentido àquilo que se procura comunicar. Mas, se aquilo que se diz das coisas não é exatamente o que elas são, tornam-se, portanto, vazias de sentido:

\footnotetext{
Há outra concepção de linguagem que não conhece nem meio Mittel, nem objeto, nem destinatário da comunicação. Ela afirma que no nome da essência espiritual do homem se comunica com Deus. (...) A essência do homem é a língua mesma, ela não pode se comunicar através dela, mas apenas dentro dela (Benjamin, 2011, p. 223).
}

Sob essa ótica, o Medium da linguagem é ela própria, e o homem não pode utilizála para se comunicar, mas só pode se comunicar dentro dela. Os gregos antigos expressavam dessa forma a identidade do espírito e da linguagem através do logos. Benjamin por sua vez, recorre à essência espiritual como idêntica à essência linguística, na medida em que essa é comunicável. É com base na palavra humana que se expressa aquilo que está em essência do objeto, não existindo, então, identidade entre o que é dito e o seu conteúdo espiritual. Para ele, esse é um tipo de linguagem do homem, de conteúdo e identidade espiritual como sendo a linguagem em que ocorreu a criação.

Para o autor, conhecer a linguagem é tudo o que seria necessário para compreendêla e seu julgamento atrapalha o discernimento daquele que nomeia, tornando-a, em verdade, oculta, encoberta pelo manto da arrogância. Em continuidade a seu pensamento, afirma que, depois que o homem cria a palavra judicante, distancia-se do conhecimento da criação, da origem das coisas. Assim, o que nomeia passa a ser simples convenção, que pouco define ou expressa o que realmente acontece. Nesse sentido, com a perda da relação natural entre os elementos do mundo, tudo se transforma em cifra de um saber enigmático (Seligmann-Silva, 1999).

Ainda chamamos atenção para o seguinte fato: quando o homem inventa a palavra judicante, uma das coisas que vai surgir é a abstração como signo linguístico e o distanciamento do real. É na abstração que existe uma separação entre a realidade e o pensamento. Trazendo para a Dança Lembrança do Sertão, apresentamos um Sertão de signo linguístico, e não 
necessariamente uma realidade. Isso porque a música, como linguagem dos objetos e dos afetos, aproxima o pensamento da realidade, não o isolando do mundo, mas estando em constante mudança com as novas percepções da realidade.

Nesse processo, o vínculo entre o pensamento e a realidade só existe na mente daquele que pensa, sendo "sobrenomeado" com o conceito que quer dar conta do real. Assim, não esquecemos que o real é móvel, é volante, é dominado pelo Kronos. Por isso, tratamos de uma linguagem do tempo, que é significante para quem ouve e pensa sobre ela, e que por ela pode elaborar pensamento. O perigo do conceito do real é apegar-se a certas características do objeto como se fossem imutáveis.

Ao conceituar algo, busca-se sua definição para tentar explicar o que as coisas são, e, muitas vezes, mantê-las como são pode ocasionar o erro de reproduzir mitos e definições desatualizadas. Isso, certamente, acompanha generalizações entre o objeto avaliado e a realidade. Isso tudo, a nosso ver, seria apenas aproximação daquilo que realmente ocorre no mundo, nas generalizações das culturas, dos povos e de suas manifestações artísticas.

Mas como cada ser e cada cultura são únicos, e como não existe uma folha igual a outra na natureza, apesar de chamá-las pelo mesmo nome, não há cultura igual, nem há concordância de pensamento, nem deve haver. Porque, para mantê-la, além de todo o esforço demandado, é necessário que haja múltiplas narrativas sobre a cultura, com o cuidado de que a comunicação não se torne algo distante do real.

Essa imediatidade na comunicação do abstrato instalou-se como judicante quando o homem, que abandonou a comunicação do concreto, isto é, o nome, e caiu no abismo do caráter mediado de toda comunicação, da palavra vã, no abismo da tagarelice (Benjamin, 2010, p. 225).

A verdade está na realidade, no entanto, não pode ser conhecida em sua totalidade como buscam os filósofos que tentam enquadrá-la em um sistema de valores. Não é fruto do trabalho intelectual ou filosófico, ao contrário, faz parte da essência do real, que, na origem do drama barroco, o objeto do saber como determinado pela intencionalidade do conceito não é considerado a verdade. Ademais, não possui objetivos ou finalidade, e como visa à produção conceitual, ela é "não conceitual" e não intencional, porque a "verdade é a morte da intenção" (Benjamin, 2010, p. 225), por isso, o nome é livre de qualquer fenomenalidade.

Na música como linguagem dos objetos e dos afetos, vimos o quanto a ciência tem sido considerada um caminho seguro para se chegar à verdade. Desse modo, é vista como instrumento útil para tal. Mas sendo a ciência uma criação humana, também não pode ser

n. 21

Janeiro - Abril 2021

p. $296-317$ 
perfeita, por isso, está sempre sujeita a avaliações e reavaliações, dessa maneira, também dispomos a presente investigação. Portanto, a unidade do saber, se é que existe, consiste apenas na coerência mediada e produzida por conhecimentos parciais e, de certa forma, por seu equilíbrio, "ao passo que na essência da verdade a unidade é uma determinação direta e imediata" (Benjamin, 2011, p. 228).

É a partir da nomeação que aparecem os aspectos fenomênicos, presentes na experiência sensível como por força da sustentação que lhes é atribuída. Ou seja, é por meio deles que se tem a oportunidade do real, e, consequentemente, a descoberta das ideias, logo, "na contemplação filosófica a ideia (sic) se libera enquanto palavra, do âmago da realidade, reivindicando de novo seus direitos de nomeação" (2011, p. 228). Apesar de o autor desenvolver sua ideia a partir da relação espiritual e de origem teológica, redirecionamos ao objeto como portador de um nome, um conceito, uma ideia.

Concluímos com a abordagem de Walter Benjamin, em relação à linguagem geral, dos objetos e a linguagem dos afetos, que trata a arte, e, especificamente, a música, pois consideramos sua ideia uma espécie de rememoração ou reminiscência, a percepção do nome que se expressa pelas ideias. Nesse processo, a tarefa do filósofo é restaurar a palavra em sua primazia pela representação do caráter simbólico da palavra, a fim de chegar à consciência de si, o que é oposto a qualquer comunicação dirigida apenas para o exterior.

Logo, a linguagem tem a comunicação como seu principal alvo, ela é utilizada com o objetivo exterior ao da própria linguagem. Isso fica mais claro se entendermos que a informação só passa a existir quando a comunicação humana é dirigida para o exterior. Ou seja, ela é utilizada como simples meio Mittel, tendo também um objetivo específico, que é acrescentar algo ao seu discurso. O autor reafirma o valor da narrativa, ou melhor, da arte de narrar, que é transmitida oralmente, como uma linguagem viva, e como os narradores utilizavam a comunicação para transmitir ensinamentos construídos pela própria experiência. Desse modo, o conhecimento era passado naturalmente.

A partir da origem teológica de Walter Benjamin no desenvolvimento de sua teoria sobre a linguagem, vemos pelo menos três implicações. A primeira, tem a ver com o direito, vendo a si mesmo como portador do conhecimento para julgar o que é bom e o que é mau, que não poderia estar mais enganado por sua incapacidade. A segunda, seria o conhecimento científico amparado pelo conceito, que não detém a verdade. E a terceira, a informação, sendo uma forma de comunicação exterior, que sozinha não traz qualquer conhecimento. O que o

n. 21

Janeiro - Abril 2021

p. $296-317$ 
autor aponta é para a contemplação filosófica, que revela por si mesma, e de forma pontual, como ocorre com o brilho de uma estrela, numa "iluminação profana".

Ao fim, como um rallentando reflexivo, duas caixas foram abertas: uma sobre a linguagem musical em si mesma e, portanto, um 'objeto' virtual; e a outra, sobre a linguagem musical e seu potencial, naquilo que é possível extrair da obra para além da partitura e seus recursos técnicos, isto é, o contexto histórico e social em que foi desenvolvida e o que aponta como linguagem. Nessas caixas, conta-se com a posição ou a participação do ouvinte como elemento essencial na percepção da obra e sua contemporaneidade.

Nesse processo, consideramos o ouvinte como aquele que se torna ator social e parte da ideia do compositor, porque ele reage aos sons, associa a outros, interpreta e os reproduz. Ele é capaz de perpetuar a obra ou contribuir para seu esquecimento, por isso, é o ouvinte, na contemporaneidade, parte integrante da obra musical. Sendo a linguagem musical para ele e por ele.

Figura 1 - Trecho da Dança Lembrança do Sertão - na toada para piano

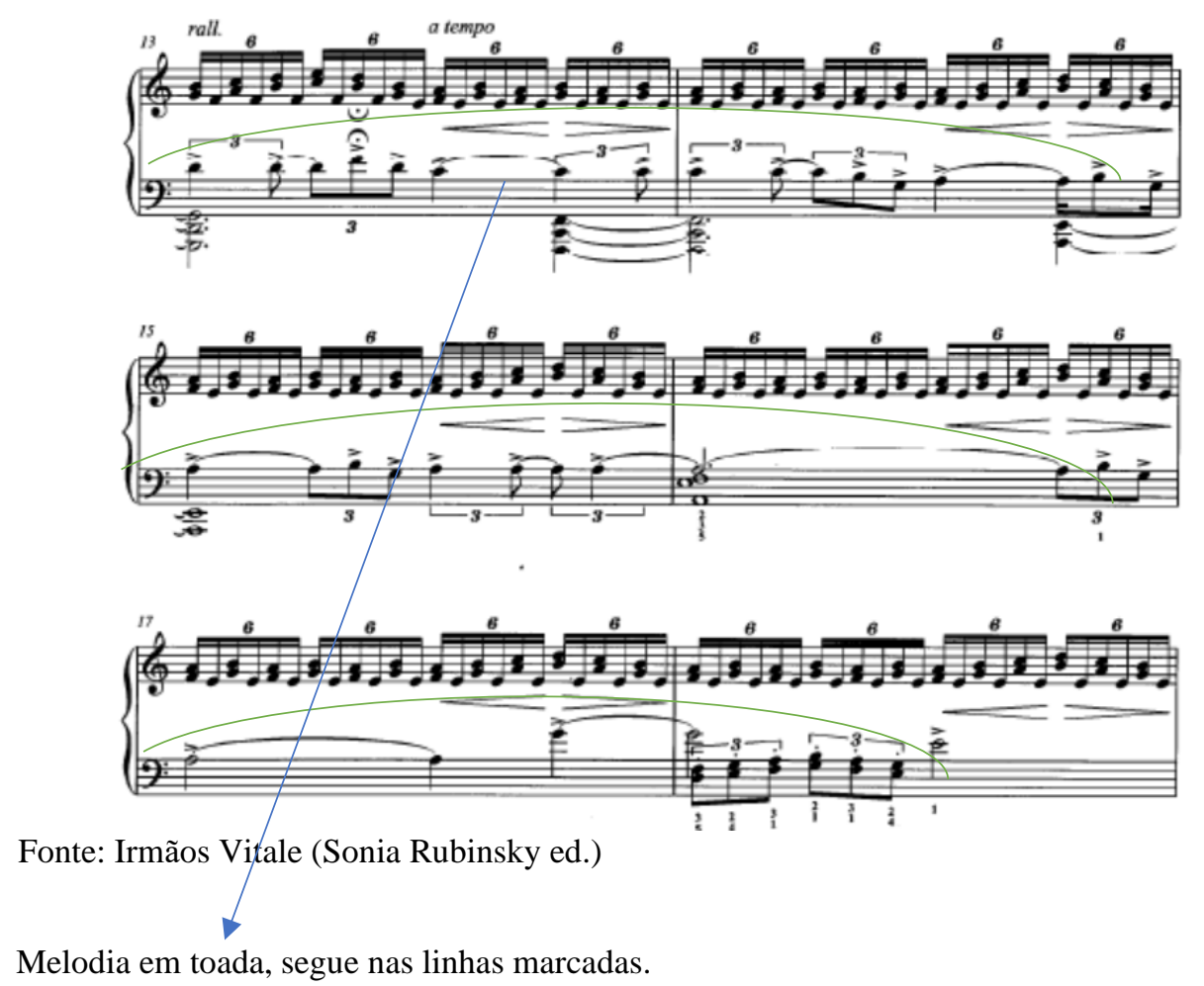

Figura 2 - Trecho da Dança Lembrança do Sertão - tema em toada

\begin{tabular}{|l|l|l|l|l|}
\hline Govista Qialectus & Ano 10 & n. 21 & Janeiro - Abril 2021 & p. $296-317$ \\
\hline
\end{tabular}




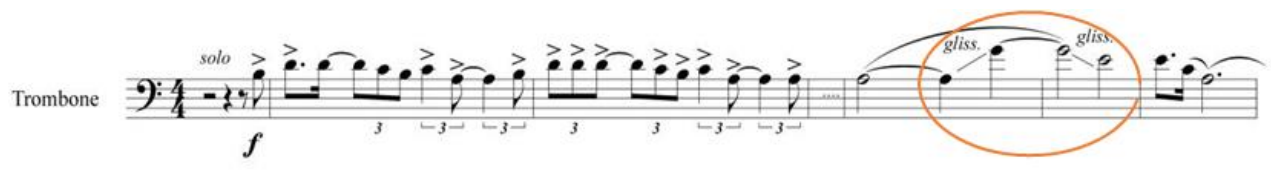

Fonte: Barrenechea, 2014

\section{Referências}

ADORNO, Theodor W. Quasi una fantasia. Escritos musicais II. Editora Unesp, $1^{\text {a }}$ edição. São Paulo, 2018.

ALBUQUERUE, Durval Jr. A invenção do Nordeste e outras artes. Martins Fontes, $2^{\text {a }}$ edição, São Paulo, 2011.

BARRENCHEA, Lúcia Silva. Dança - Lembrança do Sertão de Heitor Villa-Lobos: construindo a interpretação da redução para piano. In: Congresso da Associação Brasileira de Performance Musical- ABRAPEM, 1., 2014, Vitória. Anais [...]. Vitória: ABRAPEM, 2014.

BENJAMIN, Walter. Obras escolhidas. v. 1, 2. Tradução de S. P. Rouanet. São Paulo: Brasiliense, 1987.

BENJAMIN, Walter. Sobre a arte, técnica, linguagem e política. Tradução de M. A. Cruz e M. Alberto. Lisboa: Relógio d'Água Editores, 1992.

BENJAMIN, Walter. Sobre a linguagem em geral e sobre a linguagem do homem. In: BENJAMIN, Walter. Escritos sobre mito e linguagem. São Paulo: Editora 34, 2011. p. 4973.

CASCUDO, Luís da Câmara. Mouros, judeus e franceses, três presenças no Brasil. 3. ed. São Paulo: Editora Global, 2001.

CRUZ, Ricardo; BRISSON, António; PAIVA, Ana; LOPES, Eduardo. "I-SOUNDS: EmotionBased Music Generation for Virtual Environments" in Ana Paiva, Rui Prada, and Rosalind Picard (eds.), Affective Computing and Intelligent Interaction, Berlin: Springer, 2007.

CUNHA, Euclides da. Os Sertões. $3^{\text {a }}$ ed. São Paulo: Cultrix, 1987.

FORNARI, José Eduardo. A produção de sentido musical através da retroalimentação comunicacional entre o músico intérprete e seu público ouvinte. Ciência da Universidade Estadual de Campinas, 3 jul. 2019. Disponível em: https://www.blogs.unicamp.br/musicologia/2019/07/03/26/. Acesso em: 3 jul. 2019.

HANSLIK, Eduard. Do belo musical, um contributo para a revisão da estética da arte dos sons. Tradução de Artur Morão. Covilhã: Universidade de Beira Interior, 2011. (Colecção Textos Clássicos de Filosofia).

HOLANDA, Sérgio Buarque. Raízes do Brasil. 26ª ed. Rio de Janeiro: Companhia das Letras, 1982. 
INGOLD, Tim. Four objections to the concept of soundscape. In: INGOLD, Tim. Being Alive: Essays on movement, knowledge and description. London; New York: Routlege, 2011. p. 136-139.

LAKOFF, George; JOHNSON, Mark L. Metaphors we live by. Chicago: Chicago University Press, 1980.

LESKOV, Nikolai. O peregrino encantado. Lisboa: Nova Veja, 2012.

LÉVI-STRAUSS, Claude. O pensamento selvagem. $3^{\text {a }}$ ed. Campinas: Papirus, 2008, p.15197.

LOPES, Eduardo. Releituras. Newsletter da Associação Portuguesa de Educação Musical. Fevereiro de 2021. p. 18-20

LOPES, Eduardo. Investigação em Interpretação Musical: paradigmas e o conceito de narrativas múltiplas. In: ZURBACH, C.; FERREIRA, J. A. (coord.). Investigação em Artes Perspectivas. Évora: Universidade de Évora, 2014. p. 23-36.

LOPES, Eduardo. Just in Time: Towards a Theory of Rhythm and Metre. United Kingdom: University of Southampton, 2003.

MARIZ, Vasco. Heitor Villa-Lobos: compositor brasileiro. $11^{\mathrm{a}}$ ed. Belo Horizonte: Itatiaia Limitada, 1989.

MARUN, N. Revisão crítica das canções para a voz e piano de Heitor Villas-Lobos: publicadas pela Editora Max Eschig [online]. São Paulo: Editora UNESP; São Paulo: Cultura Acadêmica, 2010.

MEDEIROS, Ana Judite de Oliveira; LOPES, Eduardo. O Sertão imaginado na Ária Cantiga das Bachianas Brasileiras. Revista Europeia de Estudos Artísticos, ERAS, v. 10, n. 2, p, $42-$ 63, 2019.

ORTIZ, Renato. Cultura brasileira e identidade nacional. $5^{\text {a }}$ ed. 9. reimp. São Paulo: Brasiliense, 2006.

SELIGMANN, Márcio. Ler o livro do mundo: Walter Benjamin, romantismo e crítica poética. São Paulo: Iluminuras, 1999.

SENA, Caio. Textura Música: Forma e Metáfora. Rio de Janeiro: Caderno de Debates UNIRIO, 2007.

SIMMEL, Georg. The Sociology of Conflict. The American Journal of Sociology, Chicago, The University of Chicago Press, v. 9, 1903-1904.

SLOBODA, John; JUSLIN, Patrik (org.): Music and emotion: theory and research. Oxford: Oxford University Press, 2001.

n. 21 Janeiro - Abril 2021 p. $296-317$ 